INOBIS: Jurnal Inovasi Bisnis dan Manajemen Indonesia

Volume 1, Nomor 3, Juni 2018

Wa Ode Zusnita; Andhita Titisari; Ernie T Sule

\title{
Peran Knowlege Sharing Terhadap Kinerja Pegawai Perusahaan Telekomunikasi
}

\author{
Wa Ode Zusnita Muizu \\ waode.zusnita@unpad.ac.id \\ EB Unpad \\ Andhita Titisari \\ andhitatitisari@gmail.com \\ FEB Unpad \\ Prof. Ernie T Sule \\ ernie.tisnawati@fe.unpad.ac.id
}

FEB Unpad

\begin{abstract}
Abstrak
Peneltian ini dilakukan untuk mengetahui apakah knowledge sharing berpengaruh positif dan signifikan terhadap kinerja pegawai di PT Telkom Indonesia. Penelitian ini memiliki dua variabel, yaitu knowledge sharing sebagai variabel independen dan kinerja pegawai sebagai variabel dependen. Data didapatkan melalui wawancara dan penyebaran kuesioner pada karyawan di PT Telkom Indonesia dengan jumlah sampelnya sebanyak 145 orang. Metode penelitian ini menggunakan metode deskriptif dan metode verifikatif. Pengolahan data dilakukan dengan menggunakan analisis regresi linear berganda. Hasil dari penelitian ini menunjukkan bahwa Knowledge sharing berpengaruh positif sebesar 28,9\% dalam membentuk kinerja kerja pegawai, yang artinya dengan semakin baiknya pelaksanaan knowledge sharing di PT Telkom, maka akan semakin baik pula kinerja yang dimiliki pegawai.
\end{abstract}

Kata kunci: Knowledge sharing, kinerja pegawai

\section{Pendahuluan}

Saat ini sudah banyak perusahaan-perusahaan besar yang memiliki divisi tersendiri untuk mengelola KM, salah satunya adalah perusahaan milik negara PT Telkom Indonesia Tbk yang berkantor pusat di Jakarta. Kemunculan KM di PT Telkom Indonesia dimulai sejak tahun 2004 yang ditandai dengan pembuatan portal kampiun, kemudian pada tahun $2006 \mathrm{KM}$ bahkan telah menjadi bagian dari unit bisnis PT Telkom Indonesia, yang kemudian diterapkan juga pada anak perusahaannya seperti Telkom Internasional Indonesia (Telin) dan Telkomsel, karena dengan adanya portal kampiun ini dapat memfasilitasi kebutuhan pegawai di ketiga perusahaan tersebut akan akuisisi, sharing serta utilisasi pengetahuan, yang berfungsi juga sebagai knowledge center, competency center, dan virtual discussion.

PT Telkom Indonesia bahkan bisa dikatakan sudah memiliki sistem yang termasuk dalam best practices $K M$, salah satunya adalah menjadi pionir dalam menciptakan corporate university yang merupakan bukti otentik bahwa PT Telkom Indonesia benar-benar mengapresiasi KM sebagai bagian yang sangat penting bagi perusahaan. Bahkan komitmen Telkom terhadap pentingnya penyebaran, penyimpanan, dan aplikasi pengetahuan bagi kemajuan bisnis perusahaan dibuktikan dengan pindahnya knowledge management dari Kantor Pusat di bawah Direktorat Human Capital and General Affairs - yang saat ini difokuskan pada manajemen SDM Perusahaan serta penyelenggaraan operasional SDM secara terpusat melalui 
INOBIS: Jurnal Inovasi Bisnis dan Manajemen Indonesia

Volume 1, Nomor 3, Juni 2018

Wa Ode Zusnita; Andhita Titisari; Ernie T Sule

unit Human Capital Center, serta pengendalian Assessment Center Indonesia serta Community Development Center - ke corporate university.

Selain itu banyak aktivitas Knowledge sharing yang digerakkan di PT Telkom Indonesia, tidak hanya sebatas pada penggunaan sistem informasi teknologi atau online melalui Kampiun saja, namun juga melalui Knowledge sharing secara offline. Mulai dari sebuah buletin yang diberi nama KILAU, diskusi setengah hari, Silahturahmi 135 yaitu sharing session informal di tingkatan masing-masing unit bisnis, kemudian knowledge day, yang diadakan untuk sharing pengetahuan atau kebijakan baru dan unit yang saling terkait dipertemukan. Namun tidak hanya hal tersebut, agar Knowledge sharing dapat menjadi output yang bermanfaat terutama dalam meningkatkan kinerja, maka inovasi yang berbasiskan pengetahuan terus menerus dilakukan PT Telkom Indonesia.

Pada tahun 2015, PT Telkom Indonesia harus menghadapi sebuah isu, dimana kinerja PT Telkom Indonesia mengalami penurunan terutama dapat terlihat dari segi performa finansialnya. Rapat Umum Pemegang Saham Tahunan (RUPST) PT Telekomunikasi Indonesia (Persero) Tbk. memutuskan pembagian dividen sebesar Rp 8,8 triliun untuk tahun buku 2014, yang tercatat menurun 11,11 persen dari tahun sebelumnya 2013 senilai Rp 9,9 triliun. Namun kebalikannya dengan PT Telkom Indonesia, Telkomsel yang merupakan anak perusahaan dari Telkom justru berhasil membukukan laba bersih Rp 19,4 triliun sepanjang 2014 lalu. Realisasi tersebut meningkat 11,9 persen dibandingkan laba bersih 2013 yang mencapai Rp 17,34 triliun. ${ }^{1}$ Begitu juga dengan anak perusahaan lain yaitu Telkom Internasional (Telin) memberikan kontribusi sebesar Rp 14,91 triliun atau tumbuh 33,72\% dibandingkan tahun sebelumnya. ${ }^{2}$

Menurunnya kinerja perusahaan secara keseluruhan ini diasumsikan disebabkan oleh menurunnya pula kinerja pegawai, dimana dalam kurun waktu tahun 2015 lalu, ada permasalahan kinerja pegawai yang dapat terlihat dari menurunnya angka appraisal summary yang dipaparkan pada tabel dibawah ini:

Tabel 1. Appraisal Summary Pegawai PT Telkom Tahun 2014 dan 2015

\begin{tabular}{ccc}
\hline Skor & Persentase tahun 2014 & Persentase tahun 2015 \\
\hline$>80$ & $16,32 \%$ & $17,34 \%$ \\
$70-79$ & $39,44 \%$ & $19,75 \%$ \\
$60-69$ & $32,83 \%$ & $48,61 \%$ \\
$<60$ & $11,41 \%$ & $14,3 \%$ \\
\hline
\end{tabular}

Sumber: Data Internal PT Telkom, 2016

Berdasarkan data pada tabel 1 dapat dilihat bahwa mayoritas pegawai pada tahun 2015 mendapatkan penilaian sebesar 60-69, sedangkan pada tahun 2014 mayoritas pegawai mendapatkan hasil penilaian diantara 70-79. Penurunan tersebut berdasarkan pendapat dari pihak Human Capital PT Telkom, antara lain disebabkan karena banyaknya kesalahankesalahan yang dilakukan oleh pegawai Telkom dalam melakukan pekerjaannya.

Disinilah terlihat sebuah fenomena yang menarik dimana PT Telkom Indonesia sebagai perusahaan induk, justru yang mengalami penurunan dalam hal kinerja pegawainyanya dibandingkan kedua anak perusahaan yang lain. Padahal ketiga perusahaan ini jika kita hubungkan kembali dengan penerapan knowledge management, justru PT Telkom Indonesia lah yang bisa dikatakan paling baik dalam implementasi KM itu sendiri. Penurunan kinerja

\footnotetext{
${ }^{1}$ Sumber: http://www.cnnindonesia.com/ekonomi diakses tanggal 26 Oktober 2015

${ }^{2}$ Sumber: http://www.republika.co.id/berita/ekonomi/korporasi diakses tanggal 26 Oktober 2015
} 
INOBIS: Jurnal Inovasi Bisnis dan Manajemen Indonesia

Volume 1, Nomor 3, Juni 2018

Wa Ode Zusnita; Andhita Titisari; Ernie T Sule

pegawai ini secara tidak langsung akan berdampak negatif terhadap kinerja perusahaan, dan dengan menurunnya kinerja PT Telkom terutama dari segi finansial, sedangkan anak perusahaan PT Telkom justru mengalami peningkatan finansial, mengindikasikan bahwa kinerja pegawai yang memiliki permasalahan hanya terjadi di PT Telkom.

Selain itu ada isu lain yang menarik yang diperoleh saat observasi di lapangan pada tahun 2015 lalu, pada saat terjadi penurunan profit PT. Telkom, tingkat keterlibatan pegawai dalam berbagi pengetahuan (Knowledge sharing) melalui repository yang terdapat di Portal Kampiun pun menurun. Hal tersebut terbukti dari data sekunder yang didapatkan pada tahun 2012 sampai dengan tahun 2015, pegawai yang berkontribusi dalam portal Kampiun mengalami terlihat tidak konsisten, namun persentase kontribusi terendah yaitu 52,62\% ada pada tahun 2015 lalu. Sehingga berdasarkan data ini penulis berasumsi bahwa kontribusi yang paling rendah diantara 4 tahun terakhir, turut mempengaruhi turunnya kinerja PT. Telkom Indonesia.

Implementasi Knowledge sharing di PT Telkom tentunya tidak lepas dari peran atasan/pimpinan, dan sejauh ini peran atasan di PT Telkom Indonesia menurut penulis sudah cukup strategis, dimana para pimpinan di Telkom mendukung dan menginisiasi Human Capital Master Plan untuk mengoptimalkan potensi human capital yang ada dengan cara memproyeksikan kebutuhan human capital secara tepat, baik dari jumlah maupun kompetensinya.

Akan tetapi dengan sistem human capital management yang dianggap sudah baik tersebut, namun belum bersinergi secara optimal dengan pelaksanaan Knowledge sharing, yang terlihat dari menurunnya kontribusi pegawai dalam kegiatan Knowledge sharing seperti yang sudah dipaparkan diatas. Hal tersebut seperti yang disampaikan oleh Trivellas et al. (2015) bahwa semakin rendahnya intensitas Knowledge sharing maka dikhawatirkan akan menghambat peningkatan kompetensi pegawai yang berujung pada tidak semakin baiknya kinerja pegawai tersebut secara individual maupun secara keseluruhan.

Berdasarkan kondisi empiris serta permasalahan yang dihadapi di lapangan, serta berpedoman pada penelitian-penelitian terdahulu, maka kondisi demikian dianggap sangat penting untuk diadakan penelitian lebih lanjut, mengenai peran knowledge sharing terhadap kinerja pegawai (studi kasus PT. Telkom Indonesia).

\section{Tinjauan Pustaka dan Hipotesis}

\subsection{Konsep Knowledge Sharing}

Menurut Kessel, Kratzer, dan Schultz (2012), Knowledge sharing adalah sebuah proses komunikasi interaktif antar individu satu dengan yang lain di dalam suatu kelompok yang menciptakan hubungan saling bergantung untuk mencapai tujuan bersama.

Pendapat lainnya mengemukakan bahwa Knowledge sharing merupakan proses interaksi sosial, dengan mendirikan peluang untuk berbagi pengalaman, dengan membangun domain dari hubungan informal, dengan menyediakan fasilitas untuk mengamati, mendengarkan dan meniru praktik terbaik, yang diperkuat oleh kepercayaan antar individu (Panahi, Watson, dan Partridge, 2012).

Berdasarkan beberapa pengertian Knowledge sharing di atas, maka kesimpulan pengertian Knowledge sharing menurut penelitian ini adalah proses interaksi yang dilakukan individu, dengan adanya kepercayaan antar individu untuk mencari dan mengembangkan pengetahuan dan informasi sehingga dapat membantu terciptanya kerangka baru dalam solusi kreatif. 
INOBIS: Jurnal Inovasi Bisnis dan Manajemen Indonesia

Volume 1, Nomor 3, Juni 2018

Wa Ode Zusnita; Andhita Titisari; Ernie T Sule

Panahi, Watson, dan Partridge (2012) menyebutkan lima dimensi dari Knowledge sharing yang terdiri dari:

1) Dimensi Social Interaction;

2) Dimensi Experience Sharing;

3) Dimensi Informal Relationship;

4) Dimensi Observation; dan

5) Dimensi Mutual Trust.

Carmeli, Gelbard, dan Reiter-Palmon (2013) juga langsung menguraikan Knowledge sharing ke dalam beberapa indikator yaitu: (i) Kemampuan seorang pemimpin dalam memotivasi bawahannya untuk berbagi informasi dan pengetahuan; (ii) Kemampuan memecahkan masalah dengan solusi kreatif; (iii) Kemampuan menyerap informasi dan pengetahuan; dan (iv) Kemampuan menyampaikan pengetahuan yang didapat dari internal dan eksternal perusahaan.

Berdasarkan dimensi dan indikator yang telah dikemukakan di atas, maka penelitian ini mengambil sebuah simpulan mengenai dimensi dan indikator Knowledge sharing sebagai berikut: (i) Dimensi Komunikasi; (ii) Dimensi Interaksi Sosial; (iii) Dimensi Pengalaman; (iv) Dimensi Relasi; dan (v) Dimensi Kepercayaan

\subsection{Konsep Kinerja Pegawai}

Mangkuprawira dan Hubeis (2007:160) menyebutkan bahwa kinerja karyawan dipengaruhi oleh faktor intrinsik dan ektrinsik pegawai. Faktor - faktor intrinsik yang mempengaruhi kinerja pegawai terdiri dari pendidikan, pengalaman, motivasi, kesehatan, usia, keterampilan, emosi dan spiritual. Sedangkan faktor ekstrinsik yang mempengaruhi kinerja pegawai terdiri dari lingkungan fisik dan non fisik, kepemimpinan, komunikasi vertical dan horizontal, kompensasi, kontrol berupa penyeliaan, fasilitas, pelatihan, beban kerja, prosedur kerja, system hukuman dan sebagainya

Dari pendapat di atas, dapat dijelaskan bahwa kinerja adalah hasil kerja yang dapat dicapai baik perserorangan maupun kelompok dalam suatu perusahaan sesuai dengan tanggung jawabnya masing-masing dalam rangka mencapai tujuan perusahaan yang bersangkutan. Kinerja pegawai PT Telkom merupakan bagian penting dari kinerja perusahaan secara keseluruhan, selain itu peningkatan kinerja dari pegawainya ditujukan agar perusahaan dapat menjalankan dan mencapai visi misinya.

Gomes (2005: 142) mengemukakan dimensi-dimensi kinerja sebagai berikut:

1. Quantity of work, yaitu jumlah hasil kerja yang dilakukan dalam suatu periode waktu yang ditentukan.

2. Quality of work, yaitu kualitas hasil kerja yang dicapai berdasarkan syarat-syarat kesesuaian dan kesiapannya..

3. Job knowledge, yaitu luasnya pengetahuan mengenai pekerjaan dan keterampilannya. Pengetahuan yang dimiliki oleh setiap pegawai dalam melaksanakan suatu pekerjaan sehingga dapat berjalan secara efektif dan efisien.

4. Creativeness, yaitu keaslian gagasan-gagasan yang dimunculkan dan tindakantindakan untuk menyelesaikan persoalan-persoalan yang timbul.

5. Cooperation, yaitu kesediaan untuk bekerja sama dengan orang lain (sesama anggota perusahaan).. 
INOBIS: Jurnal Inovasi Bisnis dan Manajemen Indonesia

Volume 1, Nomor 3, Juni 2018

Wa Ode Zusnita; Andhita Titisari; Ernie T Sule

6. Dependability, yaitu kesadaran dan dapat dipercaya dalam hal kehadiran dan penyelesaian kerja.

7. Initiative, yaitu semagat untuk melaksanakan tugas-tugasbaru dalam memperbesar tanggung jawabnya. Kemampuan untuk bertindak tidak bergantung, Mengembangkan serangkaian kegiatan dan menentukan cara-cara baru atau inovasi.

8. Personal quantity, yaitu menyangkut kepribadian, kepemimpinan, keramahtamahan dan integritas pribadi, tingkah laku (sikap) pegawai di dalam perusahaan akan mempengaruhinya dalam cara pelaksanaan kerja.

Berdasarkan pendapat di atas mengenai indikator kinerja pegawai yang digunakan dalam penelitian ini, dapat disimpulkan bahwa dalam mencapai kinerja pegawai yang baik harus di lihat dari indikator-indikator antara lain Quantity of work, quality of work, job knowledge, Creativeness, Cooperation, Dependability, Initiative, Personal quantity.

\subsection{Kerangka Pemikiran}

PT Telkom Indonesia merupakan salah satu perusahaan milik negara yang biasanya memiliki kinerja yang memuaskan. Akan tetapi pada tahun 2015 lalu, PT Telkom mengalami permasalahan dalam kinerjanya, terutama berkaitan dengan kinerja finansial, dimana PT Telekomunikasi Indonesia (Persero) Tbk. memutuskan pembagian dividen sebesar Rp 8,8 triliun untuk tahun buku 2014, yang tercatat menurun 11,11 persen dari tahun sebelumnya 2013 senilai Rp 9,9 triliun. Menurunnya kinerja perusahaan tersebut juga diikuti oleh menurunnya kinerja karyawan yang diindikasikan dari menurunnya angka appraisal summary pada tahun 2015, yang mendapatkan penilaian sebesar 60-69, sedangkan pada tahun 2014 mayoritas pegawai mendapatkan hasil penilaian diantara 70-79

Hal yang menarik adalah, pada saat PT Telkom Indonesia mengalami hambatan dengan menurunnya kinerja perusahaan maupun kinerja pegawai, pada saat yang bersamaan jumlah karyawan yang berkontribusi di Portal Kampiun yang merupakan salah satu sarana utama pelaksanaan knowledge management di Telkom, juga ikut menurun cukup signifikan. Kondisi tersebut menimbulkan asumsi bahwa knowledge management saat ini telah menjadi sebuah bagian penting bagi PT Telkom Indonesia, karena secara langsung maupun tidak langsung dapat mempengaruhi kinerja perusahaan tersebut, mengingat sumber daya manusia bukanlah lagi menjadi liability bagi perusahaan, tapi sudah menjadi capital atau modal yang perlu dipertahankan keberadaannya karena sangat berharga untuk perusahaan.

Apabila perusahaan menginginkan knowledge management dapat berjalan dengan baik, proses pertama yang wajib dilakukan oleh setiap orang yang ada di perusahaan, dalam hal ini adalah Telkom Indonesia, adalah dengan menerapkan Knowledge sharing, yang merupakan dasar dari knowledge management. Hal ini seperti yang dijelaskan dalam penelitian yang dilakukan oleh Turner \& Minonne (2010), bahwa untuk mengukur efek dari penerapan knowledge management di dalam sebuah perusahaan, harus terlebih dahulu dilihat bagaimana pengetahuan di dalam perusahaan tersebut dapat tercipta melalui sebuah proses Knowledge sharing, yang merupakan hasil dari akuisisi atau penggabungan dari beberapa informasi yang didapatkan, untuk kemudian digunakan oleh perusahaan dengan cara mengobservasi kembali pengetahuan-pengetahuan yang telah disimpan sehingga menjadi aset yang sangat berharga bagi perusahaan.

Knowledge sharing merupakan salah satu cara yang bisa dilakukan oleh perusahaan dan diterapkan menjadi budaya, agar pengetahuan-pengetahuan yang dimiliki karyawan dapat 
INOBIS: Jurnal Inovasi Bisnis dan Manajemen Indonesia

Volume 1, Nomor 3, Juni 2018

Wa Ode Zusnita; Andhita Titisari; Ernie T Sule

disebarluaskan, diserap dan dimanfaatkan oleh karyawan lain, bahkan akan bisa meningkatkan kompetensi dari karyawan itu sendiri (Trivellas, et al., 2015).

Berdasarkan pemaparan diatas, maka dalam penelitian ini penulis ingin melihat dan menganalisis lebih lanjut apakah dengan adanya Knowledge sharing yang diterapkan oleh Telkom Indonesia, bisa benar-benar berpengaruh pada meningkatnya kinerja karyawan itu sendiri jika sebelumnya melalui gaya kepemimpinan yang baik. Secara keseluruhan, kerangka pemikiran ini dapat digambarkan sebagai berikut:

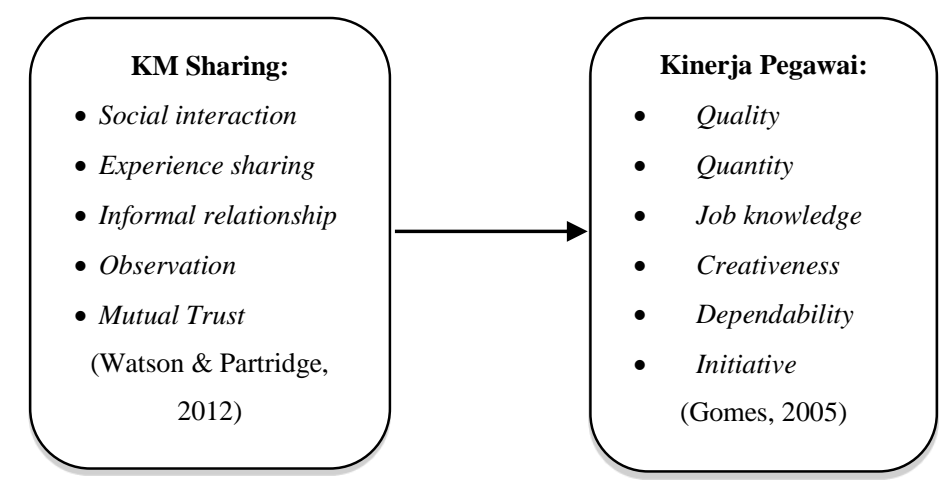

Gambar 1. Bagan Kerangka Pemikiran

\subsection{Hipotesis Penelitian}

Berdasarkan kerangka pemikiran di atas maka hipotesis penelitiannya adalah sebagai berikut:

Hipotesis Verifikatif:

Karyawan Telkom Indonesia memiliki persepsi yang baik terhadap Knowledge sharing dan kinerja karyawan.

Hipotesis Parsial:

Knowledge sharing berpengaruh positif terhadap peningkatan kinerja karyawan Telkom Indonesia secara langsung.

\section{Metode Penelitian}

Metode penelitian yang digunakan adalah penelitian deskriptif verifikatif, karena dalam penelitian ini akan dicari dan dipaparkan gambaran dari masing-masing variabel serta menguji pengaruh dari variabel-variabel tersebut. Dalam penelitian ini, penulis ingin menguji pengaruh dari variabel implementasi knowledge sharing terhadap kinerja karyawan terutama di PT Telkom Indonesia.

Berdasarkan informasi dari pihak Telkom Indonesia, diketahui bahwa jumlah pegawai yang menjadi populasi di PT. Telkom Indonesia Bandung adalah 229 orang yang kemudian akan digunakan sebagai populasi dalam penelitian ini. Menurut rumus Taro Yamane, untuk menghitung penentuan sampel, digunakan rumus sebagai berikut: 
INOBIS: Jurnal Inovasi Bisnis dan Manajemen Indonesia

Volume 1, Nomor 3, Juni 2018

Wa Ode Zusnita; Andhita Titisari; Ernie T Sule

$$
\begin{array}{lll}
\text { dimana: } & \mathrm{n} & =\text { Jumlah sampel } \\
\mathrm{n}= & \frac{\mathrm{N}}{\mathrm{N} .\left(\mathrm{d}^{2}+1\right)} \\
\mathrm{N} & =\text { Jumlah populasi } \\
\mathrm{d} & =\text { Presisi yang ditetapkan }(5 \%)
\end{array}
$$

Sehingga untuk populasi sejumlah 229 orang, jumlah sampelnya adalah sebagai berikut:

$$
\begin{aligned}
& \mathrm{n}=\frac{229}{229 .\left(0.05^{2}+1\right)} \\
& \mathrm{n}=145,43 \text { dibulatkan menjadi } 145 \text { orang karyawan }
\end{aligned}
$$

\begin{tabular}{|c|c|c|c|c|c|c|}
\hline \multirow{2}{*}{\multicolumn{2}{|c|}{ Model }} & \multicolumn{2}{|c|}{ Unstandardized Coefficients } & \multirow{2}{*}{$\begin{array}{c}\begin{array}{c}\text { Standardized } \\
\text { Coefficients }\end{array} \\
\text { Beta }\end{array}$} & \multirow[b]{2}{*}{$\mathrm{t}$} & \multirow[b]{2}{*}{ Sig. } \\
\hline & & $\mathrm{B}$ & Std. Error & & & \\
\hline \multirow[t]{2}{*}{1} & (Constant) & 9.822 & 3.789 & & 2.592 & .011 \\
\hline & $\mathrm{KS}$ & .734 & .088 & .538 & 8.348 & .000 \\
\hline
\end{tabular}

\section{Hasil dan Pembahasan}

Tabel 2. Pengaruh Knowledge sharing terhadap Kinerja Pegawai Coefficients $^{\mathbf{a}}$

a. Dependent Variable: KP

Nilai t hitung untuk variabel Knowledge sharing (KS) pada tabel 2. adalah sebesar 8.348 yang lebih besar daripada nilai t tabel (1.982) dengan nilai signifikansi (0.000) lebih kecil daripada 0.05 , yang artinya bahwa Knowledge sharing memiliki pengaruh yang positif dan signifikan terhadap kinerja pegawai (KP). Sedangkan untuk mengetahui besarnya pengaruh tersebut dapat dilihat dari nilai Beta sebesar 0.538 sehingga dapat diketahui nilai koefisien determinasi adalah $(0.538)^{2} \mathrm{x} 100 \%=28,9 \%$, yang menunjukkan bahwa Knowledge sharing berpengaruh sebesar $28,9 \%$ dalam membentuk kinerja kerja pegawai.

Begitu besarnya peran Knowledge sharingbagi karyawan di sebuah perusahaan, kinerja karyawan pun akan dengan sendirinya meningkat, seiring dengan semakin banyaknya pengetahuan baru yang dimiliki karyawan tersebut, sehingga pada saat menyelesaikan pekerjaannya akan menjadi lebih mudah dan lebih efektif dibandingkan sebelumnya. (Kuzu \& Ozilhan, 2014)

Sedangkan jika diturunkan berdasarkan dimensi-dimensi pada variabel Knowledge Sharing, diketahui hasilnya sebagai berikut: 
INOBIS: Jurnal Inovasi Bisnis dan Manajemen Indonesia

Volume 1, Nomor 3, Juni 2018

Wa Ode Zusnita; Andhita Titisari; Ernie T Sule

Tabel 3. Analisis pengaruh dimensi Knowledge Sharing terhadap Kinerja

\begin{tabular}{|l|c|c|c|}
\hline \multicolumn{1}{|c|}{ Dimensi } & r & Nilai sig & Keterangan \\
\hline Komunikasi & 0.336 & 0.000 & Berpengaruh signifikan \\
\hline Interaksi sosial & 0.423 & 0.000 & Berpengaruh signifikan \\
\hline Pengalaman & 0.323 & 0.000 & Berpengaruh signifikan \\
\hline Relasi & 0.447 & 0.000 & Berpengaruh signifikan \\
\hline Kepercayaan & 0.592 & 0.000 & Berpengaruh signifikan \\
\hline
\end{tabular}

Tabel 3. memperlihatkan bahwa dimensi knowledge sharing yang memiliki pengaruh paling besar dalam membentuk kinerja pegawai adalah dimensi kepercayaan. Berdasarkan hasil tersebut dapat dijelaskan bahwa ketika sesama rekan kerja ataupun dengan atasan, sudah muncul rasa saling percaya satu sama lain, maka pegawai akan merasakan lingkungan atau suasana kerja yang kondusif, dan dapat saling bekerjasama satu sama lain terutama dalam menyelesaikan masalah-masalah pekerjaan. Dengan demikian, maka dengan sendirinya hasil kerja pegawai akan semakin baik, sehingga berpengaruh positif terhadap pembentukan kinerjanya secara individu.

\section{Kesimpulan dan Saran}

\section{$5.1 \quad$ Kesimpulan}

Berdasarkan analisis data hasil penelitian yang sudah dilakukan dan dikembangkan maka dapat diambil kesimpulan sebagai berikut:

1. Dalam penelitian ini diketahui bahwa pelaksanaan knowledge sharing di PT Telkom sudah berada pada taraf baik, yang mencerminkan bahwa di PT Telkom, pelaksanaan knowledge sharing baik antar pegawai maupun antara atasan dengan bawahan sudah berjalan dengan sendirinya, dan mendatangkan manfaat bagi para pegawai itu sendiri.

2. Berdasarkan hasil penelitian ditemukan bahwa Knowledge sharing berpengaruh positif dalam membentuk kinerja kerja pegawai, yang artinya dengan semakin baiknya pelaksanaan knowledge sharing di PT Telkom, maka akan semakin baik pula kinerja yang dimiliki pegawai.

3. Selain itu knowledge sharing juga memiliki pengaruh yang cukup besar dalam membentuk kompetensi pegawai, yang artinya kompetensi pegawai akan semakin baik apabila pegawai tersebut juga aktif dalam mengikuti kegiatan-kegiatan knowledge sharing yang dapat menambah pengetahuannya terutama yang berkaitan dengan pekerjaan.

4. Knowledge sharing yang dimiliki oleh PT Telkom Indonesia, memiliki pengaruh yang langsung dapat meningkatkan kinerja pegawai itu sendiri, atau dengan kata lain adanya pengaruh langsung dari knowledge sharing ke kinerja pegawai memperlihatkan bahwa pada saat pegawai Telkom sudah menjalankan kebiasaannya untuk berbagi pengetahuan, maka dengan sendirinya pegawai-pegawai tersebut dapat mencari cara untuk meningkatkan kinerjanya, meskipun perusahaan tidak memberikan pelatihan untuk peningkatan kompetensi pegawai terlebih dulu 
INOBIS: Jurnal Inovasi Bisnis dan Manajemen Indonesia

Volume 1, Nomor 3, Juni 2018

Wa Ode Zusnita; Andhita Titisari; Ernie T Sule

\subsection{Saran}

Berdasarkan hasil penelitian yang sudah dijabarkan diatas, maka peneliti memberikan saran sebagai berikut:

1. Dalam rangka meningkatkan budaya knowledge sharing di PT Telkom, para pegawai beserta dengan atasannya harus dapat terus meningkatkan kerjasama antar divisi ataupun antar bagian, dalam rangka memperkuat hubungan kerja pegawai yang menjadi bagian dari knolwedge sharing, selain itu forum-forum diskusi juga bisa diadakan secara lebih sering agar para pegawai dapat lebih sering pula mendapatkan pengetahuan-pengetahuan yang baru. Selain itu para atasan juga seharusnya mulai merekognisi atau mengakui hasil-hasil kerja bawahannya, dan mendorong serta mengarahkan bawahannya untuk berani menggunakan pengetahuan yang dimilikinya dan berkontribusi dalam repository knowledge sharing milik Telkom, terutama yang berkaitan dengan peningkatan kinerja kerja. Selain itu para pimpinan atau atasan juga dapat "memaksakan" bawahannya untuk melakukan knowledge sharing dengan salah satu caranya adalah menyusun kebijakan atau peraturan yang mengharuskan pegawai untuk berbagi pengetahuan, atau bahkan bisa menjadikan knowledge sharing sebagai salah satu penilaian dalam key performance indicator (KPI) pegawai.

2. Kinerja pegawai juga dapat lebih ditingkatkan lagi apabila hubungan antar sesama pegawai maupun atasan juga ditingkatkan, agar menambah motivasi kerja pegawai yang pada akhirnya berdampak positif terhadap kinerja pegawai. Selain itu atasan juga dapat mendorong para bawahannya untuk dapat berinovasi dan mencurahkan kreatifitasnya dalam bekerja sehingga dapat memunculkan ide-ide baru dalam penyelesaian pekerjaan masing-masing, sehingga pegawai tidak perlu selalu menunggu instruksi atasan ketika bekerja.

\section{Daftar Pustaka}

Akram, F. \& Bukhari, R. (2011). The Role of Knowledge sharing on Individual Performance, Considering the Factor of Motivation-The Conceptual Framework. International Journal of Multidiciplinary Sciences and Engineering. Vol. 2, No. 9

Armstrong, M. \& Baron, A. (2004). Performance Management : The New. Realities, Institute of Personnel and Development, New York

Bateman, T. S., \& Snell, S. (2008). Management: Competing in the new era. Irwin Professional Publishing.

Brandon C. H. \& Drtina R. E . (2009). Management Accounting - Strategy and Control, McGraw-Hill Inc., Canada

Carmeli, A., Gelbard, Roy \& Reiter-palmon, Roni (2013). "Leadership, creative problemsolving capacity, creative performance: The importance of Knowledge sharing". Human Resource Management, 52(1), 95-122.

Dave, M. \& Shisodia, Y.S. (2012). Knowledge Management and Organizational Competencies: A Harmonic Collaboration. International Journal of Advanced Research in Computer Science. Vol.2, Issue 12.

Kessel, M., Kratzer, J., \& Schultz, C. (2012). Psychological safety, Knowledge sharing, and creative performance in healthcare teams. Creativity and Innovation Management, 21, 147-157.10.1111/caim.2012.21.issue-2 
INOBIS: Jurnal Inovasi Bisnis dan Manajemen Indonesia

Volume 1, Nomor 3, Juni 2018

Wa Ode Zusnita; Andhita Titisari; Ernie T Sule

Kuzu, O.H.\& Derya Ozilhan. 2014. The Effect of Employee Relationship and Knowledge sharing on Employees' Performance: An Empircal Research on Service Industry. Procedia- Social and Behavioral Sciences, Vol. 10, No. 9

Lasisi, J.O., M. A. Dabiri \& Olayinka A. Shodiya. 2015. Knowledge sharing, Innovation and Employee Performance: A Study of The Nigeria Hotel Industry. International Journal in Management and Social Science, Vol. 3, Issue No. 2

Laudon, K. C dan Laudon, J.P. (2002). Sistem Informasi Manajemen. Edisi ke-10. Terjemahan Chriswan Sungkono dan Machmudin Eka P. Jakarta: Salemba Empat.

Mangkunegara, A.A.. (2012). Manajemen Sumber daya Manusia perusahaan. Bandung: PT Remaja Rosdakarya

Mangkuprawira, S., dan A.V. Hubeis, (2007) Manajemen Mutu Sumber Daya Manusia. Penerbit Ghalia Indonesia, Bogor

Mathis, Robert. L \& Jackson John. H, (2001). Manajemen Sumber Daya Manusia, Jilid 1, Salemba Empat, Jakarta.

Nogi S. (2005). Manajemen Publik. Jakarta: Gramedia Widia Sarana Indonesia

Panahi S., Watson J., and Partridge H., (2012). Towards Tacit Knowledge sharing over Social Web Tools. Journal of Knowledge Management, 17(3), pp.379--397.

Prawirosentono, S. (2009). Kebijakan Kinerj Karyawan. Cetakan Ketiga. Yogyakarta: BPFF

Prihadi, S. F. (2006). Assessment Centre: Identifikasi, Pengukuran, dan Pengembangan Kompetensi. PT. Gramedia Pustaka Utama. Jakarta

Robbins, S. P. (2007). Perilaku Organisasi. Edisi kesepuluh. Jakarta: PT Indeks Kelompok Gramedia

Sembel, R., Santoso, H. (2002). Bisnis Maya Laba Nyata, Elex Media Komputindo, Jakarta

Siegel, Joel G dan Jae K. Shim. (2004). Kamus Istilah Akuntansi. Jakarta : PT Elex Media Komputindo

Simanjuntak, P.J. (2007). Manajemen dan Evaluasi Kinerja, Jakarta: Lembaga Penerbit Fakultas Ekonomi UI.

Talim, B.. (2005). Solusi Proaktif Permasalahan SDM di Indonesia.Gramedia Pustaka

Tiwana, A. (2000). The Knowledge Management Toolkit. Prentice-Hall, Inc

Tjakraatmadja, J. H. dan Lantu, D. C. (2006). Knowledge Management dalam Konteks Organisasi Pembelajar. SMB-ITB, Bandung

Trivellas, P., Akrivouli, Z., Tsifora, E.\&Tsoutsa, P.(2015). The impact of Knowledge sharing culture on job satisfaction in accounting firms. The mediating effect of general competencies. Procedia Economics and Finance. Vol. 19. Pp 238-24

Van Den Hoof, B \& De Ridder, JA. (2004). Knowledge sharing in Context: TheInfluence of Organizational Commitment, Communication Climate UseOn Knowledge sharing. Journal of Knowledge Management, 8 (6), 117-130

Wibowo. (2007). Manajemen Kinerja. PT. Raja Grafindo Parsada: Jakarta 